11 Scott TS. The incidence of bladder tumours in a dyestuffs factory. Br F Ind Med 1952;9:127-32.

12 Case RAM, Hosker ME, McDonald DB, Pearson JT. Tumours of the urinary bladder in workmen engaged in the manufacture of certain dyestuff intermediates in the British chemical industry. Part $\mathrm{I}$. The role of aniline, benzidine, alpha-naphthylamine, and beta-naphthylamine. Br $\mathcal{F}$ Ind Med 1954 ;11:75-104.

13 Scott TS. Carcinogenic and chronic toxic hazards of aromatic amines. Amsterdam: Elsevier Publishing Company, 1962.

14 Vineis $P$, Pastore $G$, Aimone $G$, Costa $G$, Masiero $C$. Incidenza ed età di insorgenza dei tumori laringei, vescicali e infantili nei comuni della Provincia di Torino in relazione con sviluppo industriale. Med Lav 1980;71:119-31.

15 Glashan RW, Riley A. Intravesical therapy with doxorubicin (Adriamycin) for urothelial dysplasia and early carcinoma in situ. Can $\mathcal{F}$ Surg (in press).

${ }^{16}$ Glashan RW, Wijesinghe DP, Riley A. The early changes in the development of bladder cancer in patients exposed to known industrial carcinogens. $\mathrm{Br} \mathcal{F}$ Urol (in press).

17 Glashan RW. The early detection of bladder carcinoma in industrial workers and the use of hydrostatic pressure technique in treatment. f Soc Occup Med 1974 ;24:117-24.

\section{Oral contraceptives and cardiovascular disease: some questions and answers}

Since the mid-1960s a vast amount of epidemiological, clinical, and laboratory evidence has linked the use of combined oral contraceptives with certain types of cardiovascular disease, especially venous thromboembolism, thrombotic stroke, and myocardial infarction. ${ }^{1-3}$ Despite this, some research workers have remained unconvinced by the data, and many of their major criticisms have recently been brought together in an article by Shearman. ${ }^{4}$

Firstly, several authors suggest that national trends in cardiovascular mortality (which have been generally downward) are incompatible with the estimates of risk attributable to the pill derived from case-control and cohort studies. ${ }^{5-7}$ Mann and Vessey, ${ }^{8}$ however, have pointed out that a proper analysis of mortality trends must take into account all the relevant facts and not just selected ones. Such an analysis should, for example, recognise that use of the contraceptive pill has been shown to be related only to certain forms of cardiovascular disease; that use of oral contraceptives is concentrated in young women while pill-associated mortality is concentrated in those aged 35 years or more; that cardiovascular disorders have a complex multifactorial aetiology (and hence a favourable change in one risk factor could easily counteract an unfavourable change in another); and that there have been many changes over the years in the formulation of the pill and in the way in which it is used. ${ }^{9}$ Casual examination of national trends in cardiovascular mortality and oral contraceptive use is therefore too simple; and the observed patterns are, in fact, compatible with a wide range of possible risks attributable to the pill.

Secondly, the excess deaths in those women using the pill have been said to be almost entirely attributable to smoking. ${ }^{4}$ This assertion is not in keeping with the facts. An excess risk of fatal and non-fatal cardiovascular events associated with use of the pill has been observed both in non-smokers and in comparisons of users and non-users of oral contraceptives smoking similar numbers of cigarettes a day. ${ }^{10-12}$ None the less, the risk of suffering a fatal arterial event attributable to use of the pill is heavily concentrated in smokers. As for venous thromboembolism, this condition does not appear to be related to smoking at all. ${ }^{13}$
Thirdly, Goldzieher ${ }^{14}$ has discounted the studies showing a relationship between use of the pill and venous thromboembolism because the clinical diagnosis of deep venous thrombosis is unreliable and potentially subject to bias. $\mathrm{He}$ quotes a paper by Barnes $e t a^{15}$ in support of his view. These authors studied a group of women referred to them as possible cases of venous thrombosis. This diagnosis was confirmed by ultrasonography in $31 \%$ of non-users of the pill but only $17 \%$ of users ( $p \approx 0.05$ ). A substantial proportion of the 54 users, however, had no physical signs; thus only 26 had leg tenderness and only eight had oedema. It seems reasonable to conclude that in this particular study patients taking the pill were being referred for investigation on the merest suspicion of trouble, and it seems important not to draw far-reaching conclusions from the findings. Tibbut, for example, confirmed a diagnosis of venous thrombosis by phlebography in equal proportions of users and non-users of the pill referred to him in routine hospital practice. ${ }^{16}$ Moreover, Vessey and Doll ${ }^{17} 18$ found the relation between use of the pill and venous thromboembolism to strengthen the more conclusive the evidence of disease.

Finally, Shearman ${ }^{4}$ has drawn attention to two major topics of controversy which remain to be resolved-the extent to which use of the pill is related to subarachnoid haemorrhage and whether or not there is a residual excess risk of cardiovascular disease in ex-users of oral contraceptives. With regard to the first of these questions, the Royal College of General Practitioners ${ }^{12}$ has found as strong an association between use of the pill and subarachnoid haemorrhage in its cohort study (20 deaths in total; relative risk users:non-users $4 \cdot 0: 1$ ) as between use of the pill and ischaemic heart disease (17 deaths in total; relative risk users :non-users 3-9:1). Most others have found a much weaker association, with relative risks of the order of $1 \cdot 5: 1 .^{19-21}$ As to the second question, all were agreed until the appearance of a recent publication by Slone $e t a l^{22}$ that the excess risk of myocardial infarction and venous thromboembolism was probably confined to current users of the pill. The paper by Slone et al now suggests that there may be some residual excess risk of myocardial infarction in women aged over 40 with five or more years' use of the pill in the past. The major controversy, however, concerns the risk of stroke in ex-users of oral contraceptives, some studies suggesting that there is an excess risk ${ }^{12} 23$ and others not. ${ }^{1924}$ Vessey et al ${ }^{24}$ have pointed out the difficulty in assessing mortality rates in ex-users of the pill- "the increased risk in former users could result from the development of ultimately fatal illnesses in some women while they were current users which led to them stopping the pill."

Shearman ${ }^{4}$ has questioned whether results obtained in one country may be extrapolated to another. If this is done it should be with great caution, since the background risk of the different cardiovascular disorders and the distribution of factors predisposing to them vary appreciably in different parts of the world. It seems reasonable, however, to extrapolate from one developed country to others which are closely similar-for example, from Britain to the United States, Canada, or Australia.

Perhaps we should not demand too much in the way of fine detail from the epidemiological studies. Their consensus is that fatal cardiovascular events are most likely when high-dose pills are used by older women, especially those who smoke or who have other risk factors. These observations have led to the development of modern oral contraceptives containing very small amounts of oestrogen and progestogen which are prescribed mainly for young women at low risk of cardio- 
vascular disease. In aggregate, these changes seem likely to have resulted in a substantial decrease in mortality attributable to use of the pill during the past few years.

M P Vessey

Professor of Social and Community Medicine,

Department of Community Medicine and General Practice,

Gibson Laboratory Building,

Radcliffe Infirmary, Oxford OX2 6HE

1 Vessey MP. Female hormones and vascular disease-an epidemiological overview. British fopurnal of Family Planning 1980;6, suppl:1-12.

2 Stidel BV. Oral contráceptivies and cardiovascular disease. (First of two parts.) N Engl f Med $1981 ; 305: 612-8$.

- Stadel BV. Oral contraceptives and cardiovascular disease. (Second of two parts.) N Engl Y Med 1981;305:672-7.

- Shearman RP. Oral contraceptives: where are the excess deaths ? Med $\mathcal{Y}$ Aust 1981 ; i :698-700:

5 Tietze.C. The pill and mortality from cardiovascular disease : another look. Fam Plann Perspect 1979;11:80-4.

- Belsey MA, Russell Y, Kinnear K. Cardiovascular disease and oral contraceptives: a reappraisal of vital statistics data. Fam Plann Perspect 1979; $11: 84-9$.

7 Wiseman RA, MacRac KD. Oral contraceptives and the decline in mortality frem circulatory disease. Fertil Steril 1981 ;35:277-83.

8 Mann JI, Vessey MP. Trends in eardiovascular disease mortality and oral contraceptives. British fournal of Family Planning 1981 ;6:99-104.

- Adam SA, Thorogood M, Mann JI. Oral contraception and myocardial infarction revisited: the effects of new preparations and prescribing patterns. Br $\mathcal{F}$ Obstet Gynaecol 1981 ;88:838-45.

10 Mann JI, Doll R, Thorogood M, Vessey MP, Waters WE. Risk factors for myocardial infarction in young women. British fournal of Preventive and Social Medicine 1976;30:94-100.
11 Shapiro S, Slone D, Rosenberg L, Kaufman DW, Stolley PD, Miettinen OS. Oral-contraceptive use in relation to myocardial infarction. Lancet $1979 ; \mathrm{i}: 743-6,7$.

12 Royal College of General Practitioners' Oral Contraception Study. Further analyses of mortality in oral contraceptive users. Lancet 1981 ji: 541-6.

13 Lawson DH, Davidson JF, Jick H. Oral contraceptive use and venous thromboembolism: absence of an effect of smoking. Br Med 7 1977;ii: 729-30.

14 Goldzieher JW. Oral contraceptive hazards-1981. Fertil Steril 1981 ;35: 275-6.

15 Barnes RW, Krapf T, Hoak JC. Erroneous clinical diagnosis of leg vein thrombosis in women on oral contraceptives. Obstet Gymecol 1978;51: 556-8.

16 Tibbut D. Thrombosis statistics. Br Med F 1977;i:231.

17 Vessey MP, Doll R. Investigation of relation between use of oral contraceptives and thromboembolic disease. A further report. $\mathrm{Br} \mathrm{Med}$ J 1969 ; ii:651-7.

18 Vessey MP. Some methodological problems in the investigation of rare adverse reactions to oral contraceptives. Am J Epidemiol 1971 ;:4:202-9.

10 Collaborative Group for the Study of Stroke in Young Women. Oral contraception and increased risk of cerebral ischemia or thrombosis. $N$ Engl f Med 1973;288:871-8.

20 Inman WHW. Oral contraceptives and fatal subarachnoid haemorrhage. Br Med F 1979;ii:1468-70.

21 Thorogood M, Adam SA, Mann JI. Fatal subarachnoid haemorrhage in young women: role of oral contraceptives. $\mathrm{Br}$ Med F 1981 ;283:762

22 Slone D, Shapiro:S, Kaufiman DW, Rósenberg L, Miettinen OS, Stolley PD. Risk of myocardial infarction in relation to current and discontinued use of oral contraceptives. $N$ Engl F Med 1981;305:420-4.

23 Pettiti DB, Wingerd J. Use of oral contraceptives, cigarette smoking, and risk of subarachnoid haemorrhage. Lancet 1978 ;ii:234-5, 6 .

24 Vessey MP, McPherson K, Yeates D. Mortality in oral'contraceptive users. Lancet 1981 ;i:549-50.

\section{The General Medical Council and postgraduate education}

It was fitting that Sir John Walton's first task as president of the General Medical Council should have been to chair an important conference on postgraduate medical education in London last week. The Medical Act of 1978 gave the General Medical Council's Education Committee the task of coordinating all stages of medical education, but while responsibilities for undergraduate training and the preregistration year were precisely defined the committee's role in postgraduate education was less clear. The purpose of the conference, attended by over 250 delegates representing educational interests, the BMA, the Health Departments, and research councils was to consider what steps the General Medical Concil might take in this crucial area.

The consensus that emerged was that the education committee should have a function in overseeing and monitoring postg:aduate education, perhaps in the same way as it now does with undergraduate training; leaving the Royal Colleges and Faculties (as with the medical schools) to supervise the content and standards of education. At present the main source of dissatisfaction is at senior house officer level, where posts may be used for general or specialist professional training, for vocational programmes in general practice, or for overseas doctors, depending on the different criteria used by the approving bodies. Informed observers believe that many posts fall short of expectations and that others are inappropriate at such an early stage in a doctor's career. Doubts about the wisdom of commitment to specialisation so soon after registration and the difficulty of moving between the specialties have led to calls for a common general professional training lasting perhaps one or two years (though Sir Douglas Black warned against what he called "compulsory flexibility"), and the conference suggested that the General Medical Council might examine this aspect in detail as its first task.

While coordination of medical education from undergraduate to senior house officer might resolve what some speakers see as the present chaos, there are also problems in specialist training. Much of the difficulty is caused by each approving body functioning differently. Some hold their examinations at entry to specialist training, others at its completion; some grant specialist accreditation, others do not. Sir John made it clear that the General Medical Council had no intention of setting up a compulsory specialist register, but he would like to see an improvement in the present haphazard arrangements for registration of higher qualifications.

Some speakers thought that training needed to be more closely monitored; consultants should be prepared, for example, to have their educational programmes reviewed by their peers in the same way that general practice trainers do theirs. More detailed information about opportunities was demanded by trainees, though Sir Henry Yèllowlees pointed out that much of it was already available centrally. Unfortunately the conference had no time to consider the important topic of continuing education, and it side-stepped the issue of financing yet another body concerned with postgraduate education. And before the General Medical Council's Education Committee takes on its new role it might care to look critically at the present bureaucratic machinery, which many believe is already top-heavy.

Alex Paton

Postgraduate Dean,

North-east Thames Region,

London NW1 5HD 